\title{
Virtual Information Services in Academic Libraries in Kuwait
}

\author{
Sajjad ur Rehman1, Aysha M. Al Kandari² \\ ${ }^{1}$ Department of Information Studies, College of Social Sciences, Kuwait University, Kuwait City, Kuwait \\ ${ }^{2}$ Kuwait University, Kuwait City, Kuwait \\ Email: rehman05@gmail.com, aysha.alkandari@gmail.com
}

How to cite this paper: ur Rehman, S. and Al Kandari, A.M. (2019) Virtual Information Services in Academic Libraries in Kuwait. Open Access Library Journal, 6: e5543.

https://doi.org/10.4236/oalib.1105543

Received: June 14, 2019

Accepted: July 2, 2019

Published: July 5, 2019

Copyright () 2019 by author(s) and Open Access Library Inc.

This work is licensed under the Creative Commons Attribution International License (CC BY 4.0).

http://creativecommons.org/licenses/by/4.0/

\begin{abstract}
The purpose of this study is to examine the status and prospect of virtual information services in academic libraries in Kuwait. The study conducted open-ended interviews of managers or heads of information services in 12 academic libraries about management and conduct of virtual information service and the possibilities about the future of these services. Also observed the functioning of services in 9 libraries. It was found that email was the common method for virtual communication in academic libraries in Kuwait. These libraries lacked in services using live chat and mobile application. Social media was mostly used for announcements and marketing of library services. In addition, private academic libraries provided advanced virtual services as compared to public academic libraries. Eight interviews were conducted by phone due to unavoidable circumstances related to both participants and researcher. One private academic institution did not allow access to its library, denying opportunities for observation. This paper provides insights on the way virtual information services were managed and conducted in these libraries. No similar study was noted in this regional context. The findings may help academic library management a better understanding of the issues and challenges they faced and the opportunities they might benefit in future.
\end{abstract}

\section{Subject Areas \\ Information Science, Library, Intelligence and Philology}

\section{Keywords}

Virtual Information Service, Academic Libraries, Kuwait, Reference Services, Information Services

\section{Introduction}

Academic libraries are integral part of educational institutions, as they provide 
support and services to the faculty, staff, and students. The information services that the academic libraries offer include access, information or reference services in the form of desk-provided services, instruction, information literacy programs, ILL services, search help, etc. Keeping in view recent technological changes, academic libraries have been providing many services virtually. Virtual information services can be provided in several ways; by email, live chat, texting, telephone and one of social media applications such as Twitter, etc. These services include both synchronous and asynchronous virtual engagements.

Library patrons can access virtual information services using library website as a link for these services. Among the pioneer services, we have noted that Internet Public Library (IPL) started services in 1995 as an experiment. Internet Public Library (IPL) was used as a global virtual information service; marking phenomenal success. During 90s, some public libraries started offering ask a librarian, using email and web form. More recently libraries started offering their users live chat, textual and social media-based services as a way of communication between the users and the librarians [1].

\section{Problem}

Kuwait's academic libraries can be divided into two categories of public university libraries and private university libraries. With regard to virtual information services, there is a need to examine how Kuwaiti academic libraries are offering these services. Such an evaluative effort may cover possibilities and opportunities these organization may envision as future prospects.

\section{Objectives}

Following three objectives were conceived for this study:

1) To examine the extent to which Kuwaiti academic libraries are offering general and virtual information services.

2) To investigate the issues and challenges Kuwaiti academic libraries are facing in the conduct of information services.

3) To project into services Kuwaiti academic libraries are considering for future implementation as virtual information services.

\section{Related Studies}

Information services in academic libraries can be offered to the users physically at the library or virtually through different technological media. Libraries have taken an approach to integrate their traditional information services with virtual information service. Duncan \& Gerrard [2] in a case study, discussed the integration of virtual reference services at the University of Saskatchewan. The integration started as a pilot project for three years. The pilot project faced a few challenges of funding, marketing, availability of volunteers, and staffing. It was found that during the last few years the number of traditional questions decreased while the number of virtual questions increased. Majority of questions 
asked were research-related and undergraduate students asked $40 \%$ of the questions. A new trend was noted of Integration of virtual services with traditional information services. Now the information professionals responded to inquiries using diverse media of communication, mostly electronic and networked. A group of librarians collaborated in answering information questions. Libraries were headed toward Reference 2.0 frame of services where line of demarcation between provider and receiver was removed [3].

In another related study, [4] studied the formats of digital reference services in Malaysian academic libraries. New media of service were mentioned in this study. They identified different media used in digital reference services including email, web form, Ask A Librarian, chat, video conferencing, webcam services, and digital reference robots. They visited ten academic library websites and reviewed services offered on website, the way these services were offered, and the guidelines provided for these services. They found that these libraries offered access to their OPACs, links to Internet resources, interactive services, and facilities for accessing remotely available resources.

In the setting of academic libraries, [5] highlighted the use of local resources in the preferences of students. They noted an increase in the use of chat service and it was becoming essential as compared to email. They found that $69 \%$ of the participant students asked questions related to local resources and services. Face-to face interactions are valuable as [6] compared between users' perspectives regarding in-person reference services and virtual reference services and reported lower satisfaction for virtual reference as compared to in-person reference. Physical interfaces are still valuable as the respondents of this study perceived.

Expounding on the value of virtual services, [7] had found that SMS and chat services added value to reference services, as they were perceived easy for use. Students wished to contact librarians via their mobile phones. They also noted that flexibility was desirable for users to benefit both from traditional and mobile library services. [8] noted the value of narratives as some academic libraries used text references, as simple questions required brief textual answers. The researchers concluded that users were mostly satisfied with reference services, though amount of use was not as substantial or encouraging.

The Reference and User Services Association (RUSA) guidelines covered five aspects of the implementation and maintenance of virtual reference service. When planning to implement virtual reference service, libraries should consider preparing for the service, organizing it, and ensuring privacy. The guidelines included a few vital points that were about integration of traditional reference service with virtual reference service, defining the population that the service will be offered to, providing the resources for training the staff, offering best quality service, and ensuring that the privacy and confidentiality of the users are protected [9]. On a similar note, [10] assessed and compared the level of adherence to professional guidelines developed by the International Federation of Library 
Associations and Organizations (IFLA), American Library Association (ALA), and Reference and User Service Association (RUSA). They found a low level of adherence to the guidelines and absence of relationship between satisfaction of guidelines and patron satisfaction.

During the last decade, social media applications have been extensively used in information processing and transfer. Beaton [11] examined use of social media in information services and noted that different types of libraries used Twitter as a communications and public relations tool for tweeting about resources, services, events and other community events.

Motivated professionals play a vital role in creating satisfied clientele. Job satisfaction of librarians responsible for offering information services is a critical consideration. Hendricks, and Buchanan [12] investigated librarians' job satisfaction with virtual reference and found that $77 \%$ of the librarians enjoyed answering chat inquiries. When questioned about the problems librarians faced, $76 \%$ had received written abuse and $28 \%$ of the abuse was about swearing. Another $24 \%$ stated that they felt their time had been wasted, while $18 \%$ had negative sentiments about virtual services.

With regard to the availability of virtual reference services in the Middle East, [13] examined the availability of virtual reference services in King Fahad University of Petroleum and Minerals in Kingdome of Saudi Arabia and noted that the library began their Ask a Librarian service in 2011 by letting their users submit their inquiries using email or a web form. Yet, the library did not offer real-time communication such as live chat.

AlKanan [14] revealed that academic libraries in Kuwait offered access to their OPAC through their website except two libraries that had not automated their cataloging operations and had not created their OPACs. Primarily, virtual reference services were offered using email, and web forms only. Email was used for transacting interlibrary loan and document delivery services. Two academic libraries in Kuwait used a dedicated website; the others used it on the university servers. It was noted that there was a dearth of professional librarians in Kuwait and ILL was not developed in the absence of a consortium of Kuwaiti academic libraries.

From the review of these studies, we may discern following points for further consideration:

- Traditional and virtual information services are mutually complementary.

- Virtual services are becoming more like a norm.

- Web and internet technologies are the essential facilitators.

- Social media are the latest instruments in the management of virtual services.

- Mobile technology provides smart addition to virtual information services.

- Satisfied professionals make a difference in extending services.

We used operational definitions of different terms used in this study. These are as follows:

Information literacy: It covers skills of recognizing when information is 
needed and the ability to locate, evaluate, use, apply, and communicate information in various formats.

Virtual information services: Those information services in which ICT is applied including telephone, email, live chat, video conferencing, smart phone applications, texting and one of social media applications such as Twitter, Facebook, etc.

Live chat: Software application used on websites for interactively engaging with users about their information queries.

FAQ: Frequently asked questions posted on website.

Social media: Forms of electronic communication through which users create online communities to share information, ideas, personal messages, and other content including blogs, wikis, Facebook, Twitter, Instagram, etc.

\section{Methodology}

This study investigated virtual information services in academic libraries in $\mathrm{Ku}-$ wait. A qualitative approach was used to gather needed data by conducting interview. The interview included 12 open-ended questions regarding information service, virtual information service, current services, issues and challenges, and plans for future. Nine interviews were done in person, while eight were done by phone. The interview took an average of 20 minutes. When interview was conducted face-to-face, it was combined with observation. Non-verbal cues of interviewees were noted sand analyzed. Placement of staff, facilities, and general agronomic conditions were also observed.

\section{Participants}

The target population of this study included librarians that worked in academic libraries and they were responsible for management and conduct of information services. Altogether 17 managers or professionals were interviewed, eight by phone, and nine in person to collect the data needed. Eight librarians were from Kuwait University (KU) libraries. These are: Libraries administration, Health Service Center (HSC), Engineering (ENG), Science (SCI), Law, Jaber Al-Ahmad Library (JA), Arts, and Education. Two libraries from Public Authority for Applied Education and Training (PAAET) participated. The research library of Kuwait Institute for Scientific Research (KISR) was also one of the participant institutions. Other private libraries that participated in the study are as follows:

- American University of Kuwait (AUK),

- Gulf University of Science\& Technology (GUST),

- Australian University of Box-Hill,

- Australian College of Kuwait (ACK),

- American University of Middle East (AUM), and

- Kuwait College of Technology (K-Tech).

The librarians were identified form personal connections and library websites. 
Participants were contacted by email to get their phone contacts. We used email and other social media such as WhatsApp for setting up appointments.

\section{Findings}

Data collected from the interviews were analyzed qualitatively. We have analyzed data around the following points:

- General information services;

- Current use of virtual information services;

- Information services on the website;

- Perceptions about virtual information services;

- Current use of social media;

- Future plans for the use of social media;

- Current use of mobile application to provide virtual information services;

- Future plans to use mobile applications;

- Staff readiness for virtual information services; and,

- Observations about current or future information services in their library.

\subsection{Provision of General Information Services}

First question asked in the interview was about general information these libraries were offering. It was found that Kuwaiti academic libraries offered circulation services, access to resources, information desk service, access to computers, and photocopying. While 13 libraries offered ILL services, PAAET practiced ILL between their libraries. Fourteen libraries conducted information literacy programs by conducting workshops, training sessions, orientations, and study tours. All these libraries provided space for studying including carrels and discussion rooms.

\subsection{Provision of Virtual Information Services}

Most significant aspect of this study was investigating the breadth, depth and extent of the provision of virtual information services in these libraries. It was found that 14 libraries offered ask a librarian by email. KU libraries had added this service recently and they shared the same website with the exception of health and science libraries. Two libraries offered live chat for its users (KU-HSC and GUST). Other two libraries offered text and instant message services. Three academic libraries (GUST \& AUK \& KU-HSC) reported that these responded to user questions about using social media. KU libraries used a unified Instagram account for their responses when the users asked questions. It was a significant finding that PAAET and K-Teck did not offer any virtual information services. While PAAET and K-Tech libraries did not offer virtual information services at present, these had no plan for introducing any virtual services in future. The only two services they indicated for possible use in future were live chat and email-based services.

About the use of website, 16 libraries used a website. These libraries used Web 
applications for providing access to their OPACs, databases, and electronic resources such as e-books or e-journals. The Australian University of Box-hill Kuwait reported that it was providing access to its users to the databases that Box-hill Australia had subscribed to.

KU libraries reported that these used Web for providing services ask a librarian by email, off-campus access, unified search, and video tutorials for the use of databases. GUST, AUK, AUM libraries offered FAQ link on their websites and webpages. KU libraries reported that they were planning to add this feature to their website. KU-HSC library, however, removed FAQ, which had been offered since late $90 \mathrm{~s}$, as they complained that it consumed much time of professionals. Four libraries of GUST, AUK, ACK, AUM were found providing their website users with information literacy tutorials in the forms of video or text. The only library that did not have a webpage was $\mathrm{K}-\mathrm{TECH}$ and, quite surprisingly, their librarian did not report any such plan in future.

\subsection{Plans for Implementing Virtual Services}

Nine libraries mentioned that these planned to implement live chat, as librarians considered it a facilitator for meaningful communication between librarians and library users. Four librarians mentioned text or instant messaging as possible plans for implementation. Four librarians chose mobile applications for virtual information services while three others wished to use social media platforms for virtual information services. On the other hand, only one librarian mentioned email. KU-HSC librarian suggested virtual training for all students that can be conducted individually or for a group of students. One librarian did not disclose her opinion as her library is working on a few services that are still to be revealed (GUST). Box-hill librarian stated that their library is very small and such services can only be implemented after they get approval for initiating bachelor degree.

\subsection{Using Social Media for Virtual Information Services}

A significant question was about the use of social media for offering virtual information services. It was found that 11 surveyed libraries used social media application of Instagram. KU libraries shared a unified Instagram account that was displayed under KU Libraries Administration. GUST, KU-HSC were the only two libraries that used Facebook for these services. In addition, KU libraries administration and three other libraries reported that they used Twitter for virtual information services. Only KU-HSC reported using Snapchat. We noted that those libraries that used social media generally used these applications for making announcements and marketing library services.

GUST, KISR and K-TECH were the three libraries that reported planning use of Facebook in their libraries for marketing and announcements. K-TECH libraries was planning use of Instagram for marketing and announcements. KISR is planning use of Twitter as well. Other libraries were not sure about future plans for the use of social media. 


\subsection{Use of Mobile Applications}

AUK is the only library that was offering mobile application where the users could $\log$ in into their accounts and search OPAC. At this point other academic libraries are not offering any mobile application. Libraries having a webpage mentioned that the library users could access the library website through their smartphone's browser. None of the surveyed libraries reported any plan to develop or launch mobile applications. Some respondents said that they did not rule out the possibility.

\subsection{Staff Preparation}

KU-HSC had the confidence that its staff members were well-qualified to work with virtual information services as three of them happened to be engineers. It was found that the staff of KU libraries (JA, SCI, ARTS, EDU) did not have a background in library and information science and many of them faced difficulties in providing virtual information services. Further it was reported that KU librarians provided training whenever these libraries acquired a new database or they introduced improvements on their website. Most communications were handled on the email system. We asked Head of libraries administration about her assessment of the staff capabilities. She noted that though they were generally prepared, yet some of them need to be further trained as new virtual information services are implemented. It was assessed that KU-LAW staff members might need training as virtual services were not implemented.

It was found that PAAET reported that the library conducted training sessions annually. Yet, all of the staff members were not perceived to be as well prepared. One possible reason was that all staff members did not have academic degree in information studies. Those librarians who were professionally qualified, they were perceived to be better performers.

Box-hill librarian reported that since reference librarian had a master's degree in information studies, they found her capable in doing a satisfactory job. GUST's head was quite satisfied with their staff's capabilities and performance. She viewed that the staff members could well cope with service innovations or enhancements. Their librarians were provided in-house training and they benefitted from these activities. K-TECH had only one librarian and she was reported to be capable in providing virtual information services. It was found that AUK professionals attended multiple training events and they were perceived to be qualified for providing virtual information services.

ACK and AUM respondents reported that their staff was well prepared as they had professional degree in library and information science. There was still a need to offer training opportunities. All the KISR librarians had degree in information studies. Since they are planning to have fresh initiatives for offering virtual information services and enhancing their portal, they needed to manage training for their staff.

\subsection{Challenges}

In response to this question, we received diverse ideas. According to KU-HSC 
manager, HSC is not just a library rather it is a learning resource center. She was optimistic that if they had the budget, space and support of administration, they could become a smart library and information resource center by focusing on virtual information services.

Four KU libraries (JA, SCI, ARTS, EDU) used virtual service and noted that their users could communicate with librarians. Yet, they are planning to add additional services to increase the use of their libraries.

KU-ENG is planning to add a live chat service while enhancing OPAC interface. It was suggested that the faculty members of information studies department might train their staff about the latest developments in the field. At PAAET, need was felt to provide virtual services in addition to the traditional services. BOX-HILL was planning to digitize their resources. So far, they have digitized 300 books and students can only access them if they are in the College. They are planning to provide mobile applications for instant and remote access. GUST wishes if their users become life-long learners. Virtual service may help in achieving this target. AUK considered that empowering staff is a key for providing better virtual services. At ACK they were keen to develop and implement information literacy program that may enhance the use of virtual services.AUM intends to catch up with new trends when it comes to virtual information services. At KISR, they are looking forward to becoming a national library for science and technology. They believe that their virtual services may help them in realizing this objective.

\section{Discussion}

Libraries in academic institutions in Kuwait were studied to examine the availability and conduct of virtual information services. The results of this study showed that virtual services are not as frequently used, as students might be keen to use and apply. KU libraries, except KU-HSC library, have recently added virtual services. Only two libraries are currently offering chat services in Kuwaiti academic libraries, while nine librarians intended to use application of live chat in the future.

Academic libraries in Kuwait need to keep up with global trends of virtual reference services. Côté, Kochkina, and Mawhinney [5] had noted a shift in the use of chat services as compared to email services. Ruppel \& Vecchione [7] had also revealed that students enjoyed using chat service because of the speed of response and the quality of help they receive. If these trends of use serve as cues, Kuwaiti libraries need to catch up with these evolving patterns.

Academic library websites in Kuwait mostly offer access to OPACs, electronic resources, and databases. Kim [15] had noted that students used websites to access library websites. It was found that $41 \%$ of students used websites for accessing electronic resources, $25 \%$ used to search OPAC, and only $4.2 \%$ used them for the service of ask a librarian. These results reveal the Kuwaiti students' use of Web applications is compatible with its use in other countries. However, 
since a number of portal applications strengthen development and use of Web, this interactive use needs to be promoted. This is expected to enrich information use further, both in quality and intensity.

It was found that FAQ was used on the websites of only three Kuwaiti academic libraries. It is contrary to the findings of [16] that the most common virtual reference service is FAQ in academic libraries' websites they had evaluated. It implies that this service has the potential of wider use. The Kuwaiti academic libraries need to develop this service in a manner that may attract the attention of a large number of users.

The respondents were generally satisfied about staff's capabilities and preparedness for implementing and promoting use of virtual reference services. However, the librarians emphasized the importance of having a professional degree in library and information science or a background in this filed. There is a need that these libraries develop programs for sustained empowerment of their staff through rigorous training. These libraries may also benefit from exchange programs.

It was found that only one library used mobile application for outreach and message transmission. Lippincott [17] had urged that libraries had to adopt mobile technologies by taking advantage of advances in mobile applications. Academic libraries in Kuwait cannot afford to lag behind in the use of mobile applications. If these libraries have to cope with latest advancements of ICT, mobile technology provides latest avenues of development and progress. In particular, this is the most significant step for virtual information services. New mobile applications express creativity, innovation, and opportunity and we need to benefit from it.

Another interesting point is that there are differences between public and private academic institutions in Kuwait. Public universities are just starting implementation of virtual information services, while private educational institutions have been providing these services for a while and they seem to have plans for further capitalizing on these services. To augment, it is noteworthy that one of those private academic institutions is providing access to the e-library of their central institution in Australia; enabling students access to e-resources and databases available in the remote location of Australia. These findings indicate that it is incumbent upon the public institutions to make concerted efforts for infrastructural improvement needed for enhancement in the provision of virtual information services.

Social media is mostly used for announcements and marketing library services. Beaton [11] mentioned that Twitter is being used as a reference service in a few libraries in the United States. Kuwaiti academic libraries are cognizant of the value and use of different media. They need to take advantage of these social media platforms and use them for publicity, outreach, extension of virtual services, and conduct of extension activities. Since these are public domain utilities, ingenious use is warranted on the part of these libraries. 
It is significant to note that some interviews were conducted by phone due to unavoidable circumstances related to both participants and researcher. Also one private academic institution did not allow access to its library. These may be treated as some inherent limitations of the study.

Summing up our discussion, apparently Kuwaiti academic libraries are still in the process of developing and improving their virtual information services. These libraries need to examine ground realities and markets surrounding academic programs and students. In order to advance in the right direction, academic libraries in Kuwait should consider all options for providing virtual information services that are compatible with needs of the user community. Using social media and mobile technology applications may provide economic and practical options. Kuwaiti academic libraries need to pay attention to such opportunities. There are universally available facilities enhancing virtual information services that can be acquired, adopted and marketed with some strategic vision and intelligent foresight.

\section{Conflicts of Interest}

The authors declare no conflicts of interest regarding the publication of this paper.

\section{References}

[1] Boss, R.W. (2010) Virtual Reference. https://alair.ala.org/bitstream/handle/11213/258/Virtual\%20Reference.pdf?sequence $=112$ \&isAllowed $=\mathrm{y}$

[2] Duncan, V. and Gerrard, A. (2011) All Together Now! Integrating Virtual Reference in the Academic Library. Reference \& User Services Quarterly, 50, 280-292. https://doi.org/10.5860/rusq.50n3.280

[3] Agosto, D.E., Rozaklis, L., Macdonald, C. and Abels, E.G. (2011) A Model of the Reference and Information Service Process: An Educators' Perspective. Reference \& User Services Quarterly, 50, 235-244. https://doi.org/10.5860/rusq.50n3.235

[4] Wan, K. and Diljit, S. (2007) Digital Reference Services in Academic Libraries Building an Information Society for All. Proceedings of the International Conference on Libraries, Information and Society, Kuala Lumpur, 26-27 June 2007, 173-186.

[5] Côte, M., Kochkina, S. and Mawhinney, T. (2016) Do You Want to Chat? Reevaluating Organization of Virtual Reference Service at an Academic Library. Reference \& User Services Quarterly, 56, 36-46. https://doi.org/10.5860/rusq.56n1.36

[6] Nilsen, K. (2006) Comparing Users' Perspectives of In-Person and Virtual Reference. New Library World, 107, 91-104. https://doi.org/10.1108/03074800610654871

[7] Ruppel, M. and Vecchione, A. (2012) It's Research Made Easier! SMS and Chat Reference Perceptions. Reference Services Review, 40, 423-448. https://doi.org/10.1108/00907321211254689

[8] Luo, L. (2011) Text Reference Service: Delivery, Characteristics and Best Practices. Reference Services Review, 39, 482-496. https://doi.org/10.1108/00907321111161449

[9] RUSA-ALA (2010) Guidelines for Implementing and Maintaining Virtual Refer- 
ence Services. Reference \& User Services Quarterly, 50, 92-96.

https://doi.org/10.5860/rusq.50n1.92

[10] Shachaf, P. and Horowitz, S.M. (2008) Virtual Reference Service Evaluation: Adherence to RUSA Behavioral Guidelines and IFLA Digital Reference Guidelines. Library \& Information Science Research, 30, 122-137.

https://doi.org/10.1016/j.lisr.2007.12.002

[11] Beaton, B. (2012), New Technologies for Virtual Reference: A Look at Skype and Twitter. http://www.lib.umich.edu/files/departments/SkypeTwitter\%20112912.pdf

[12] Hendricks, A. and Buchanan, S. (2013) From Exhaustion to Exhilaration: Assessing Librarian Job Satisfaction with Virtual Reference. Library Hi Tech, 31, 42-63. https://doi.org/10.1108/07378831311303921

[13] Rahaman, M.S. and Ansari, K. (2011) Virtual Reference Services at the Main Library of King Fahad University of Petroleum and Minerals, Kingdom of Saudi Aarabia: A Case Study. International Journal of Information Research, 1, 1-13.

[14] Alkanan, A.J. (2015) Kuwait's Higher Education Libraries: A Descriptive Analysis. IFLA Journal, 42, 59-65. https://doi.org/10.1177/0340035215622460

[15] Kim, J. (2017) User Perception and Use of the Academic Library: A Correlation Analysis. The Journal of Academic Librarianship, 43, 209-215. https://doi.org/10.1016/j.acalib.2017.03.002

[16] Pinto, M. and Manso, R.A. (2012) Virtual References Services: Defining the Criteria and Indicators to Evaluate Them. The Electronic Library, 30, 51-69. https://doi.org/10.1108/02640471211204060

[17] Lippincott, J.K. (2010) A Mobile Future for Academic Libraries. Reference Services Review, 38, 205-213. https://doi.org/10.1108/00907321011044981 